\title{
Ground support in high stress mining with high-tensile chain-link mesh with high static and dynamic load capacity
}

\author{
R. Bucher Geobrugg Australia Pty Ltd, Australia
}

A. Roth Geobrugg AG, Switzerland

A. Roduner Geobrugg AG, Switzerland

J. Temiño Geobrugg Andina S.A., Chile

\begin{abstract}
Increasing stresses and seismicity with the resulting rockburst hazard is a threat for deep hard rock underground mines. High-tensile chain-link mesh has a proven capability of absorbing rock falls in surface applications and was adapted for the use in underground workings. Due to the high-tensile wire strength and ability of the chain-link mesh to deform, this ground support system can be used in high stress environments. A mechanised 'roll mesh handler' for the application of the high-tensile chain-link mesh was developed and successfully tested in Australia and Switzerland for use as support in underground tunnels. The application of the mesh and the installation of split-sets or rock bolts occur simultaneously. The mesh handler technology increases productivity due to reduced support cycle times (trials suggest a 30-50\% quicker installation time over current sheet mesh methods); improves quality (high-tensile mesh can be tensioned and contours more closely to the rock surface) and improves safety (due to reduced manual handling without exposure of personnel in un-supported ground due to fully mechanised handling during the installation process).
\end{abstract}

\section{Introduction}

The primary ground support system in underground mining operations without a rockburst hazard consists of weld mesh panels and friction bolts. With increased depth, mines experience increasing levels of seismicity and the associated potential for rockburst damage. To cope with this hazard, specially designed rock bolts with better energy absorption and elongation capacity were introduced. These bolts also better suit highly deformable ground than conventional bolts, however, surface support is required between the bolts and a common strategy at the moment is to use fibre or weld mesh reinforced shotcrete. This tends to be expensive and slow to install, is stiff, and reacts poorly to dynamic loading. There are other products as well like common mesh with lacing, Oslo-straps and HEA Mesh.

Weld mesh panels are easy to handle and are strong and stiff enough to prevent small rockfalls and subsequent unravelling of the tunnel roofs, but they do not have the ability to absorb large dynamic impacts. The welded connections are brittle and normally fail first under dynamic loading, followed by the strands when the loads further increase.

High-tensile steel wire mesh showed good performance in rockfall and rockburst testing. Due to its strength and flexibility, the mesh was able to absorb the kinetic energy thereby slowing down the impacting rock masses. The high strength of the mesh is required to transfer the rockburst loads to the anchors and to avoid puncturing of the mesh by the rock fragments.

To use chain-link mesh as a standard product for ground support in mechanised mines, a safe and automated installation method had to be developed. The aim is to provide mine operators with an efficient and effective way to install rolled high-tensile chain-link mesh. Furthermore, it was considered desirable that the mesh handler should be capable of being retro-fitted on all commonly used underground drilling equipment, thus obviating the purchase of new machines. 


\section{$2 \quad$ High-tensile chain-link mesh for ground support}

High-tensile wire mesh offers a surface support for most ground conditions. They are made of high-tensile steel wire with a diameter of 4 and $3 \mathrm{~mm}$ respectively and a tensile strength of $1,770 \mathrm{~N} / \mathrm{mm}^{2}$. The mesh is diamond shaped and along the edges, the wires are bent over and double twisted such that this connection is as strong as the mesh which is also proofed by independent test institutes. Both meshes are produced in rolls which reduce the storage space and can be manufactured in widths of up to $3.5 \mathrm{~m}$ and in tailor-made lengths corresponding to the tunnel surface.

Due to the use of high-tensile wire, the mesh is very light in relation with its strength (TECCO: G80/4 $2.6 \mathrm{~kg} / \mathrm{m}^{2} /$ DELTAX: G80/3 $1.45 \mathrm{~kg} / \mathrm{m}^{2}$ ). For corrosion protection, the wires are coated with a special aluminium-zinc coating which has a higher corrosion resistance than standard galvanising. Comparison tests with conventional galvanized wires yield at least a three to four times longer lifespan.

The ROCK MESHA mechanised mesh handler offers a fast and safe method of application of both the TECCO and DELTAX meshes and can be retro fitted to any multi-boom underground Jumbo.

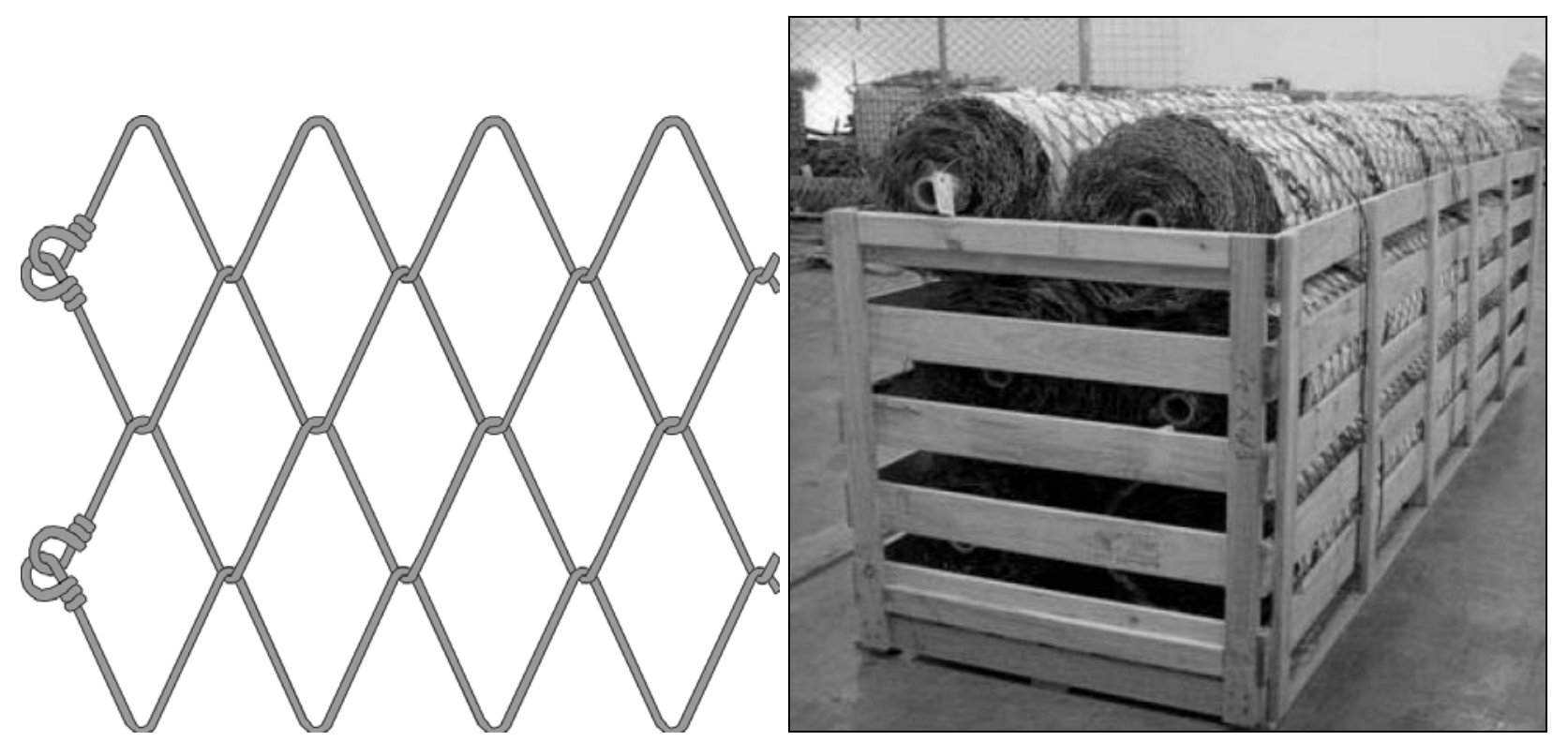

Figure 1 Geometry of the high tensile steel wire mesh and the delivery of the mesh in rolls

The mesh geometry was designed to have a very high breaking load as well as low deformation characteristics to avoid unacceptable deformation rates and unravelling of the rock after a rockburst impact. The resistance properties of the mesh were determined in a series of laboratory tests by Torres (2002) at the University of Cantabria in Santander, Spain. The properties of the meshes G80/4 and G80/3 are summarised in Table 1.

Table 1 Properties of the high-tensile mesh G80/4 and G80/3

\begin{tabular}{lll}
\hline Material & Tecco G80/4 & Deltax G80/3 \\
\hline Mesh width & $80 \mathrm{~mm}$ & $80 \mathrm{~mm}$ \\
Diagonal & $102 \times 177 \mathrm{~mm}$ & $103 \times 180 \mathrm{~mm}$ \\
Wire diameter & $4 \mathrm{~mm}$ & $3 \mathrm{~mm}$ \\
Wire strength & $1,770 \mathrm{MPa}$ & $1,770 \mathrm{MPa}$ \\
Breaking load of single wire & $22 \mathrm{kN}$ & $12.5 \mathrm{kN}$ \\
Tensile strength & $190 \mathrm{kN} / \mathrm{m}$ & $110 \mathrm{kN} / \mathrm{m}$ \\
Weight & $2.6 \mathrm{~kg} / \mathrm{m}^{2}$ & $1.45 \mathrm{~kg} / \mathrm{m}^{2}$ \\
\hline
\end{tabular}


A special designed spike plate has been developed by GEOBRUGG to transfer loads from the mesh through the spike plate to the anchoring system (Figure 2). They are made out of $5 \mathrm{~mm}$ thick galvanized steel and with a shape which best fits to the mesh. The spike plate grabs the mesh in 6 positions plus the rock bolt in the centre. Due to its three dimensional shape it is very stiff and does not bend.
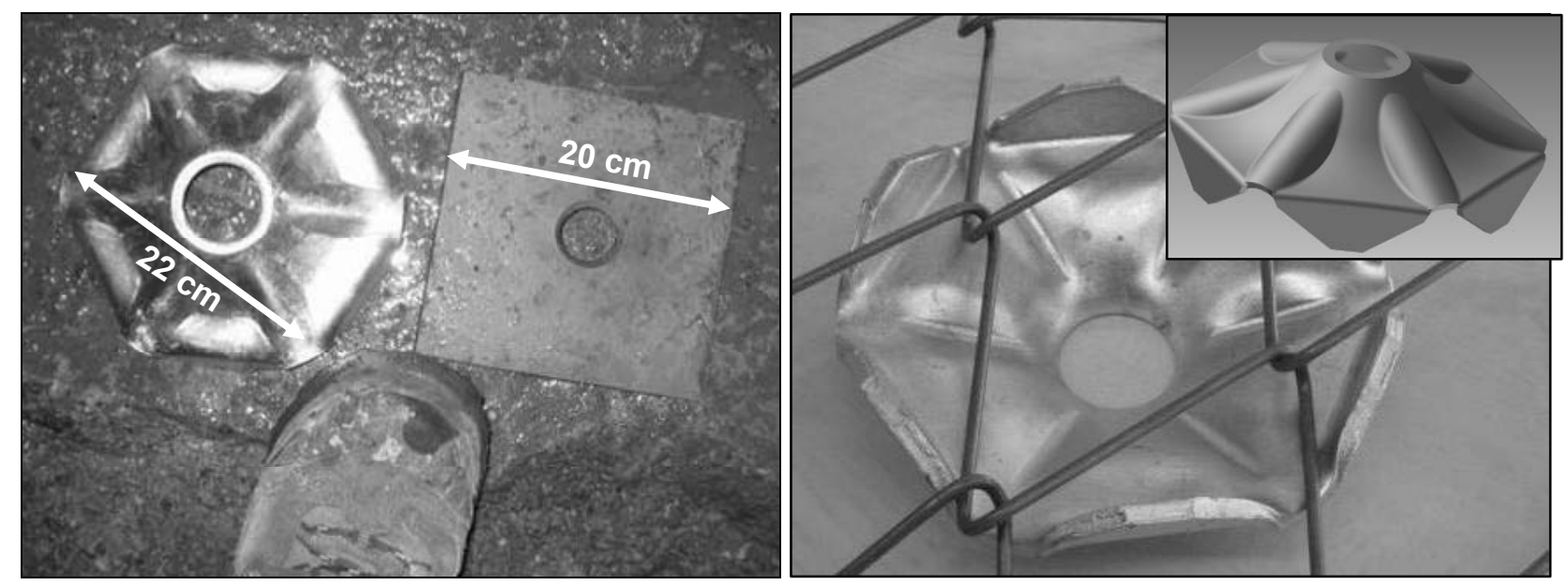

Figure 2 Special designed spike plates for the underground system

\section{$3 \quad$ Testing and modelling of high-tensile chain-link mesh}

In order to determine the mechanical properties of the mesh, TECCO was extensively tested for static and dynamic loading conditions, and DELTAX was tested for static loading, at the Western Australian School of Mines (WASM). For the dimensioning of the support system consisting of mesh and bolts, a finite element numerical model was developed, calibrated and verified by the Swiss Federal Research Institute (WSL).

\subsection{Static testing}

The static response of high-tensile chain-link mesh was determined by test work in the WASM laboratory in Kalgoorlie. Figure 3 shows the response of three samples of the high-tensile TECCO G80/4 mesh where a $1.3 \times 1.3 \mathrm{~m}$ panel was loaded with a $300 \times 300 \mathrm{~mm}$ steel plate. The test setup is described by Morton et al. (2007). The high-tensile mesh was able to bear a load of up to 100 to $110 \mathrm{kN}$ before it failed at the edge of the loading plate. Weld mesh in comparison failed with approximately $40 \mathrm{kN}$, and mild steel chain-link failed with less than $20 \mathrm{kN}$ using the same test setup. For the heavy mild steel chain-link mesh $(5 \mathrm{~mm}$ diameter, mesh width $100 \mathrm{~mm}$, tensile strength $460 \mathrm{~N} / \mathrm{mm}^{2}$ ), failure occurred at 30 to $40 \mathrm{kN}$ due to bended over wires at the mesh ends (according to the test report, Villaescusa (2009)). After closing the ends with wire rope clips (see inset picture in Figure 4), rupture occurred at 60 to $70 \mathrm{kN}$ (Figure 4, right). All mesh types require some initial displacement to be activated and loaded. 

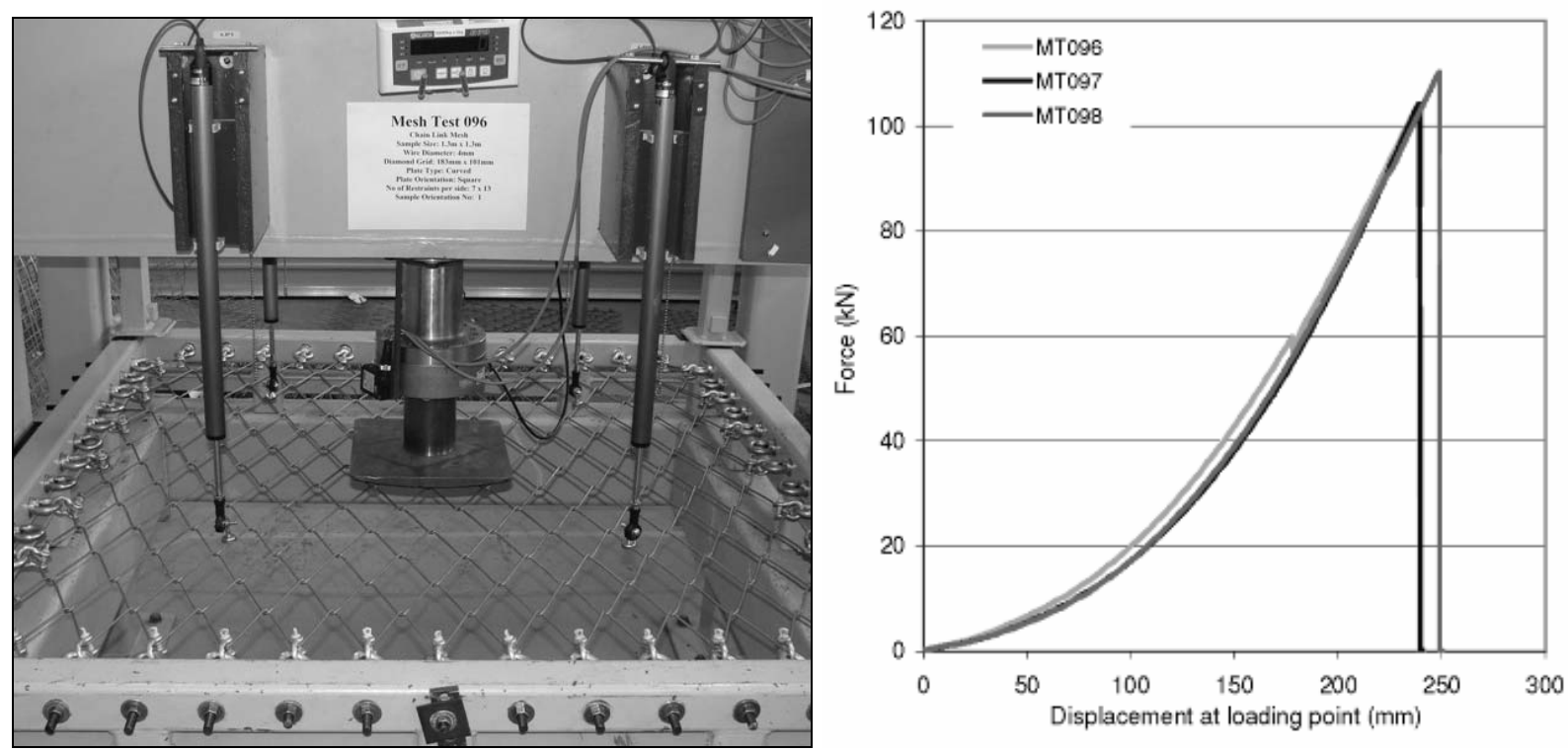

Figure 3 Measured forces in the anchorages for the high tensile steel wire mesh G80/4
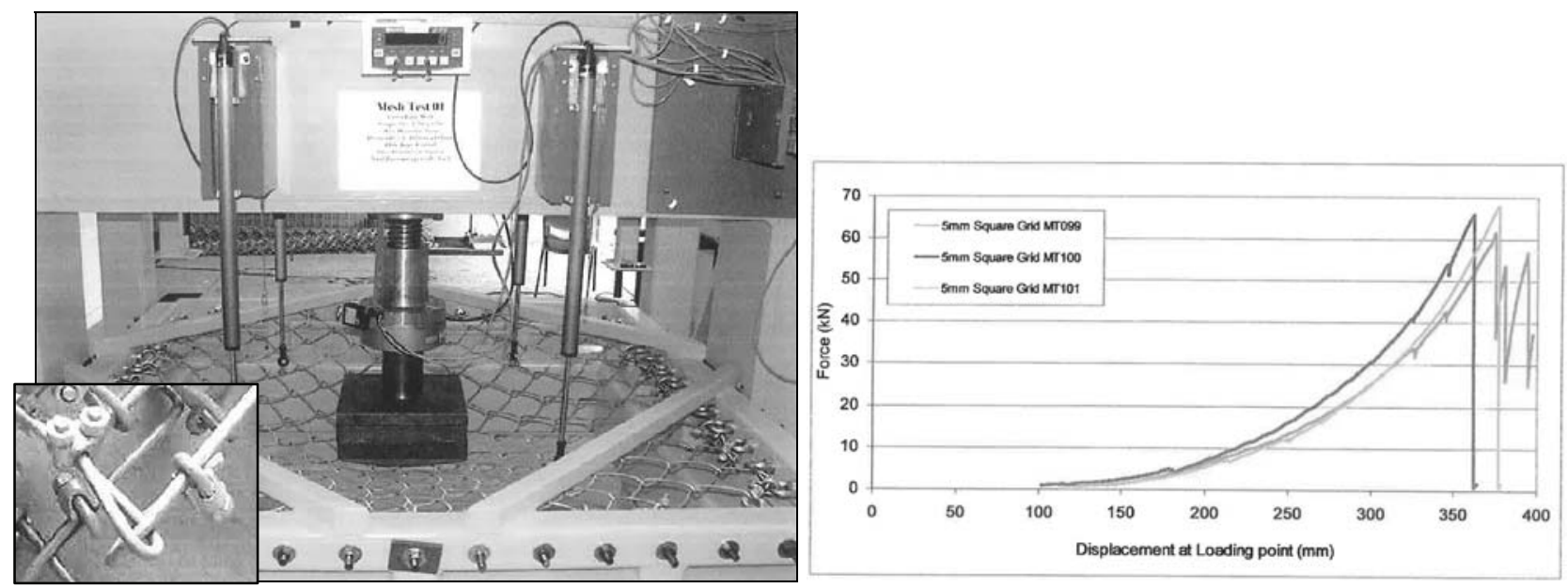

Figure 4 Measured forces in the anchorages for the $5 \mathbf{~ m m}$ wire diameter heavy mild steel chain-link mesh

The high-tensile mesh G80/3 was able to bear a load of up to $50 \mathrm{kN}$ before it failed at the edge of the loading plate (see Figure 5).
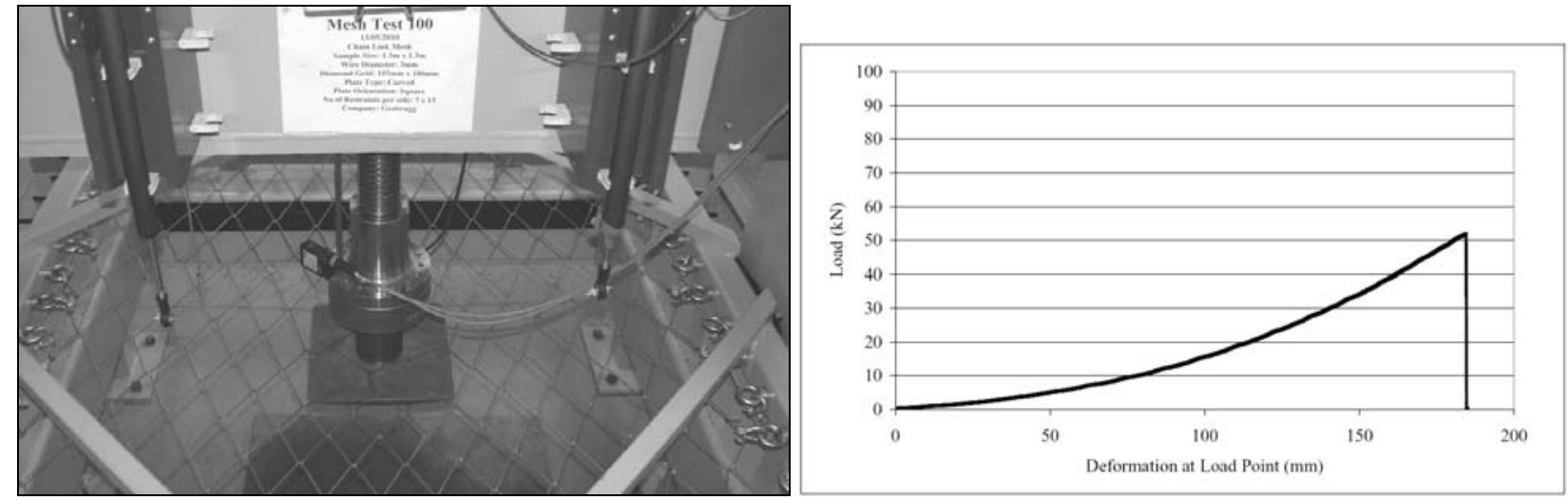

Figure 5 Measured forces in the anchorages for the high tensile steel wire mesh G80/3 
It was also found that the high-tensile chain-link mesh can sustain an increase in load even after a wire has failed. It also does not unravel once a wire has failed.

In earlier tests, the high-tensile mesh was tested in a way similar to an application underground with four bolts and plates. It was established on that test that rupture generally starts at the crossing points, but does not shear at the edge of the plates due to the higher steel quality of the mesh compared to the mild steel plates (see top left in Figure 6). Coming from mild steel chain-link mesh, there was always the concern that if one of the chain-link mesh strands is broken, the mesh will unravel and open. It has been proven that this is not the case for high-tensile chain link mesh in the above described test where the mesh was loaded up with one of the wires cut. The test results, capacity and deformation of the high-tensile chain-link mesh has been shown to be unaffected by the broken wire (Roth et al., 2004), and is shown in Figure 6, right. This only applies for high tensile chain-link mesh. It does not apply for mild steel chain-link mesh, as the individual wire does not have the required strength to lock itself in.
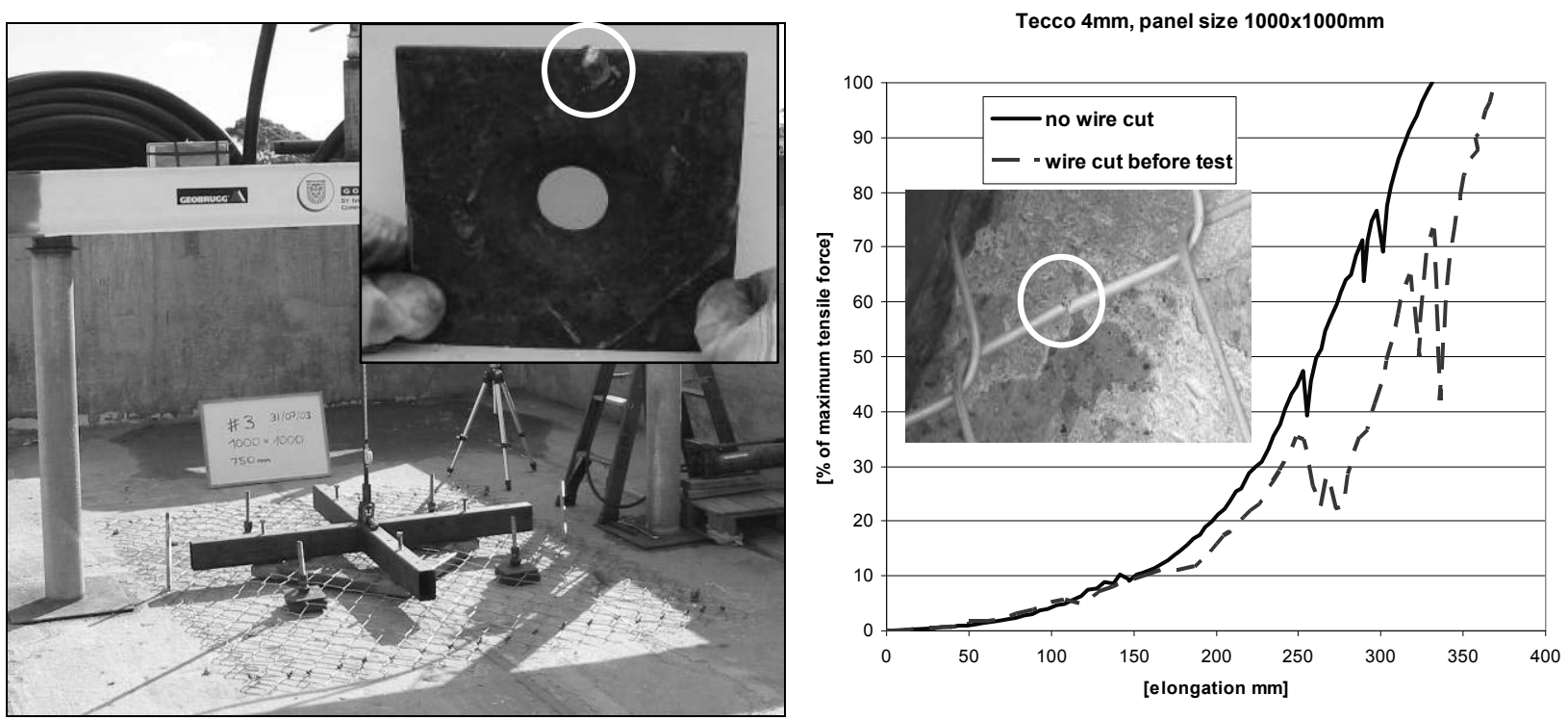

Figure 6 Static tests of a high tensile steel wire mesh which show no shearing of at the edge of the bolt plate (left) and unravelling test (right)

\subsection{Dynamic testing}

The G80/4 mesh was tested at the dynamic testing facility of WASM (Player et al., 2008) by using a momentum transfer method (see Player et al., 2004; Thompson et al., 2004). The mesh panel is installed in a loading frame in which a steel weight can be dropped onto the mesh from different heights. The rebound of the loading frame is stopped by buffers while the loading mass impacts the mesh sample without separation. This test arrangement simulates the situation with installed mesh in tunnels. The dynamic test apparatus are instrumented with high-speed video cameras, load cells and accelerometers.

Figure 7 shows images from a camera (Figure 7a) and a high-speed video camera (Figure 7b) before and after a mass of $1,000 \mathrm{~kg}$ (bag with mill steel balls) hits the high-tensile chain-link mesh. The mesh deforms with the applied load and transfers the forces to the boundary. The boundary conditions are fixed to have comparable and repeatable results. 

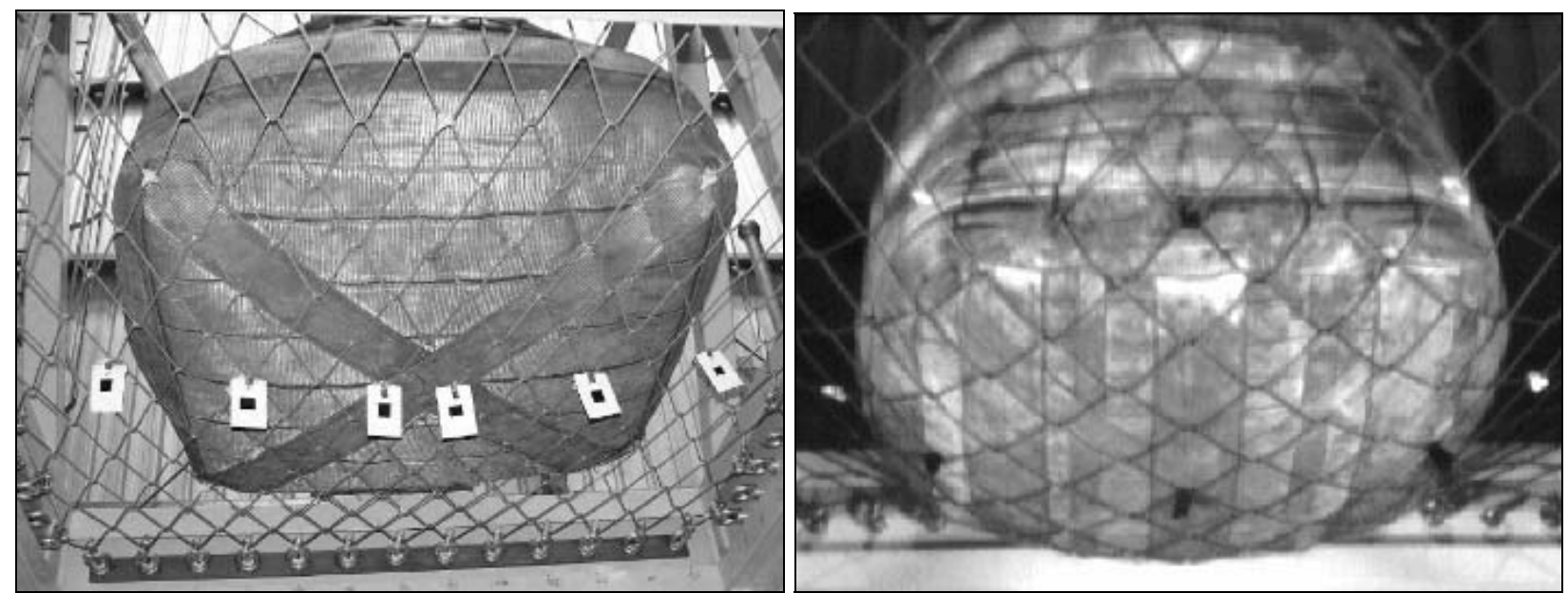

Figure 7 Photo a) from underneath the test arrangement before the impact of a $1,000 \mathrm{~kg}$ mass as well as photo b) from the high-speed video camera after impact

It was established that the high-tensile chain-link mesh G80/4 is able to absorb energies of up to $12 \mathrm{~kJ}$ in such a configuration. This is equal to stopping a rock mass of $1,000 \mathrm{~kg}$ which was accelerated to $4.9 \mathrm{~m} / \mathrm{s}$. This value represents the energy absorption of the mesh only and does not include any absorption by the rock mass or the yielding bolts. Welded wire mesh (wire diameter $5.6 \mathrm{~mm}$ and $100 \mathrm{~mm}$ wire spacing) showed energy absorption capacities up to $2 \mathrm{~kJ}$ in the same test setup.

\subsection{Numerical model}

For the numerical model, we sought an algorithm which was capable to handle large deformations and dynamic impacts. A code was chosen that is based on a discrete finite element method (FEM) and a model of rope and truss elements. In order to simulate dynamic impacts, Newton's second law is applied together with the material properties of the single components ('time-stepping'). The software FARO ('falling rock') was developed by the Swiss Federal Institute of Technology ETH and the Swiss Federal Research Institute WSL (Volkwein et al., 2002).

Figure 8a shows the static mesh tests executed by Roth et al. (2004) with the mesh and a bolt pattern of $1 \times 1 \mathrm{~m}$ where the mesh was loaded with a steel frame. These tests were used to calibrate the numerical model. It became possible to perform dynamic simulations and assess forces, failure modes and deformations of the different components with the calibrated FEM model.
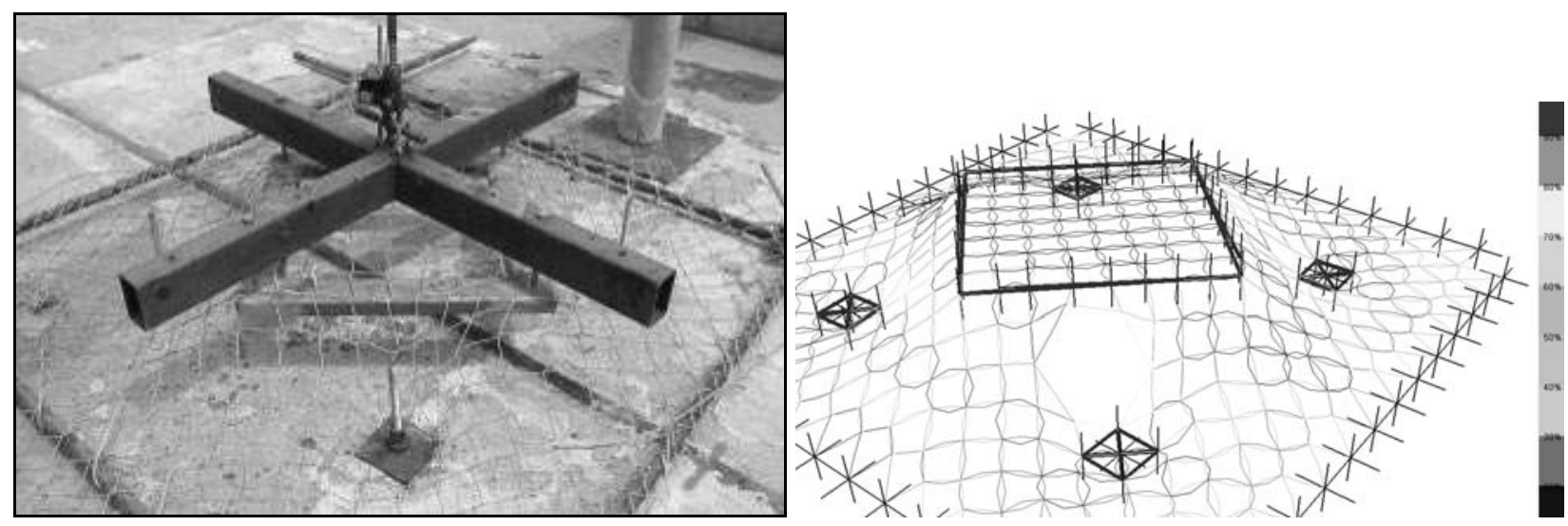

Figure 8 a) Static mesh tests and b) the calibration of the numerical model

With the numerical model of a ground support system with high-tensile steel wire mesh, it is possible to simulate the dynamic response of any setup and loading. More precise information about FARO load modelling and different kind of possibilities for boundary modelling can be found in Volkwein (2004). Input 
parameters can be adjusted to specific project parameters and the bolt pattern and maximum deflections can be determined. This makes designed ground support schemes for dynamic loading theoretically possible. It is very important to have a support system where the support components have matching capacities. The calibrated numerical model makes it possible to connect different bolt types with the high-tensile steel wire mesh and determine if they work together under given conditions. Since there is always a load concentration on the bolt plates, higher loads could be achieved by using special plates able to grab more wires like the spike plate described in section 2 .

\section{$4 \quad$ Installation of high-tensile chain-link mesh underground}

The difference between the installation of welded mesh and the installation of chain-linked mesh is the stiffness of the products. The welded wire mesh is relatively stiff and is delivered and applied in sheets. The roll of chain-link mesh is only stiff in one direction but flexible in the other and therefore has to be installed in a different way to welded wire mesh.

Manual installation of chain-link mesh is mainly done with scissor lifts or baskets attached to tool carriers, but this is labour intensive. Therefore a new way was conceived, comprising a mesh handler to unroll the mesh and hold it onto the surface of the tunnel while it is pinned to the rock with the second jumbo boom. The main objectives were the speed and safety of the installation in order to comply with the targets of modern mining both in terms of safety and economics.

\subsection{Manual installation of chain-link mesh}

When installing chain-link mesh, the mesh has to be unrolled and pinned to anchors. During manual installation, the anchors are often installed first and the mesh is attached to the anchors afterwards using scissor lifts or baskets on tool carriers (Figure 9).

These methods are slow and labour intensive and it is hard to tension the chain-link mesh correctly, an important factor for a low maintenance system. Furthermore the workers have to install the mesh under uncovered surface between the anchors which does not comply with state-of-the-art safety standards.
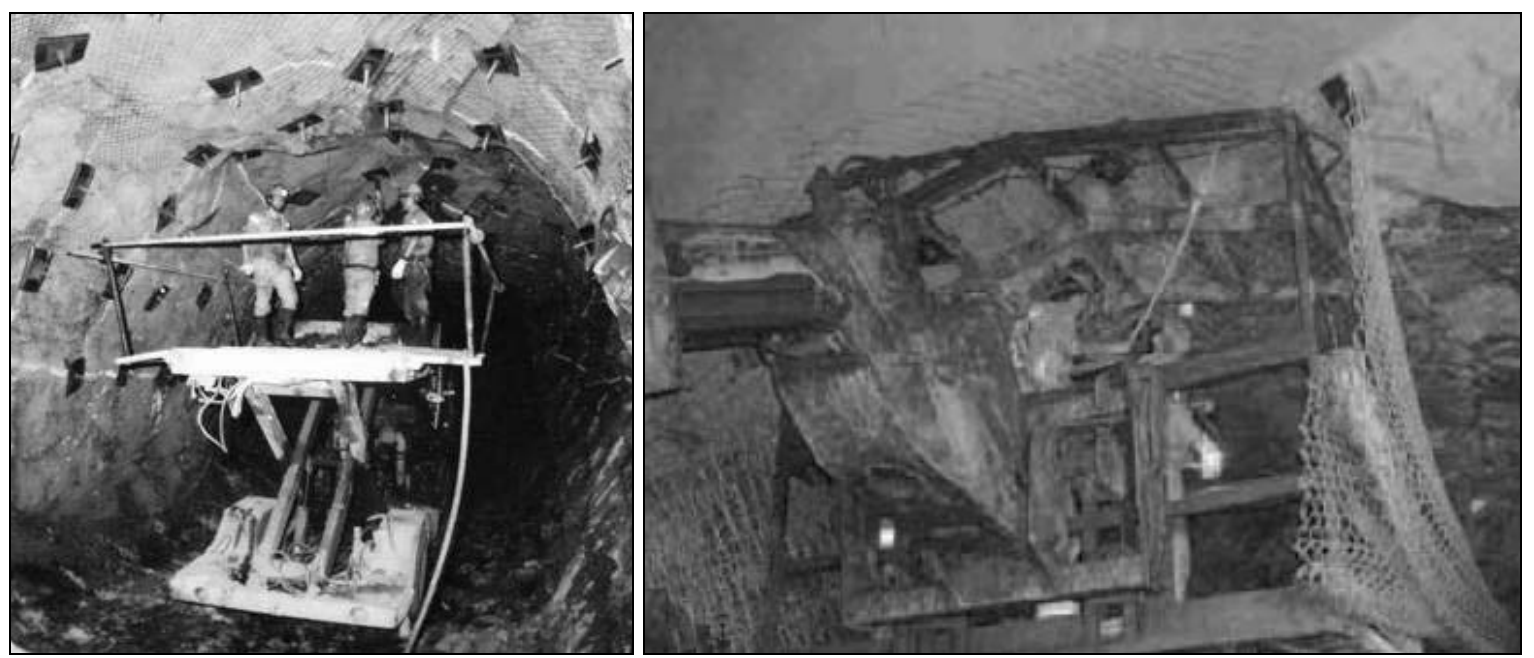

Figure 9 Manual installation of chain-link mesh with scissor lift and installation basket on tool carrier

\subsection{Installation of weld mesh sheets in Australia}

The installation of weld mesh sheets is normally done in Australian mines using the drilling jumbo. In a first step of the installation all the drill-holes needs to be done. Afterwards one can grab a sheet of welded mesh with one boom of the drilling jumbo, try to position the mesh and bolt it in with the second boom using split set rock bolts. This installation procedure is not easy but with experienced operators possible to carry out. Furthermore the workers have to bring the sheet of meshes manually in front of the jumbo going into unsupported ground. 

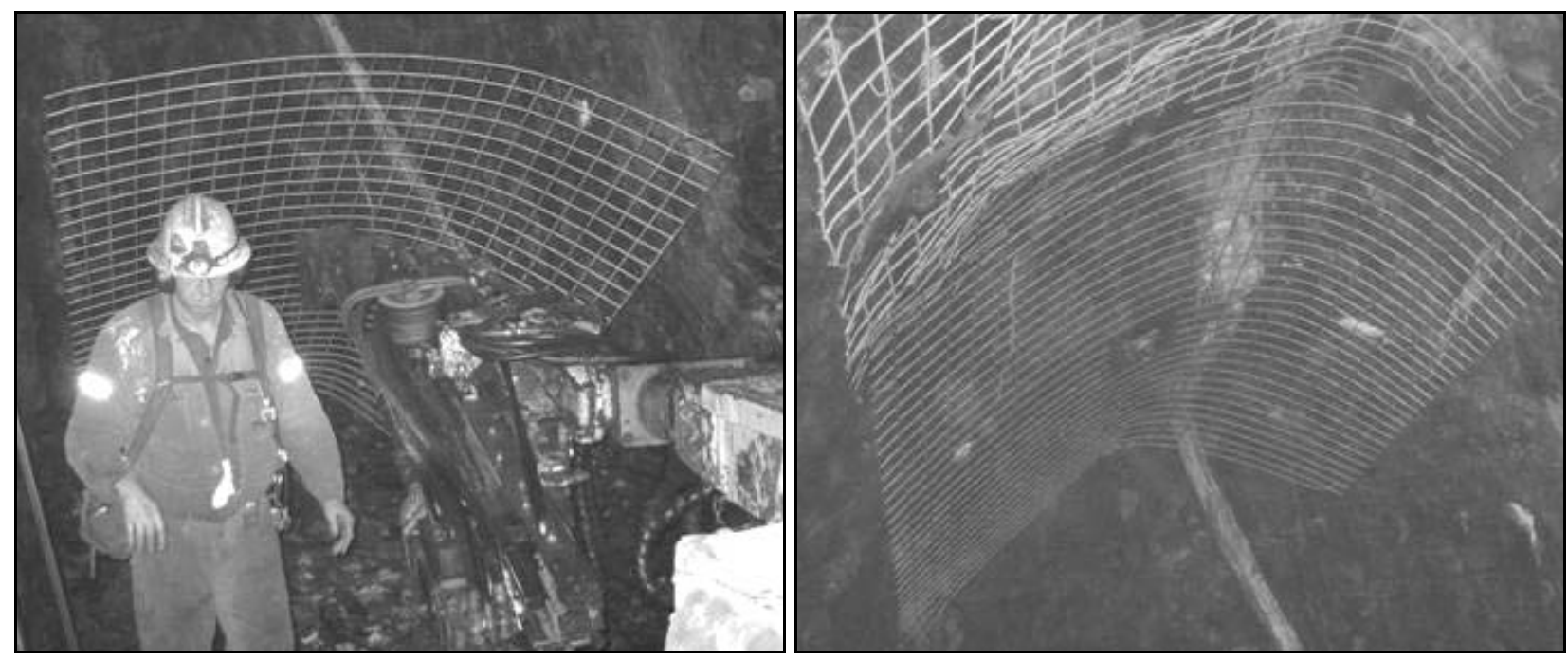

Figure 10 Installation of weld mesh sheets in an Australian mine

\subsection{Fully mechanised installation of chain-link mesh with the mesh handler MESHA}

An automated roll mesh handler for the application of high-tensile chain-link mesh was developed and successfully tested in Australia and Switzerland for the installation of support in underground workings. The handler called ROCK MESHA is compatible with all standard multi-boom jumbo drilling equipment, applying mesh from a cassette system. The handler with the mesh roll is mounted on the one boom and the drill/bolter mounted on the other boom of the jumbo (Figure 11). The application of the high-tensile mesh and installation of split-sets or bolts occur simultaneously.
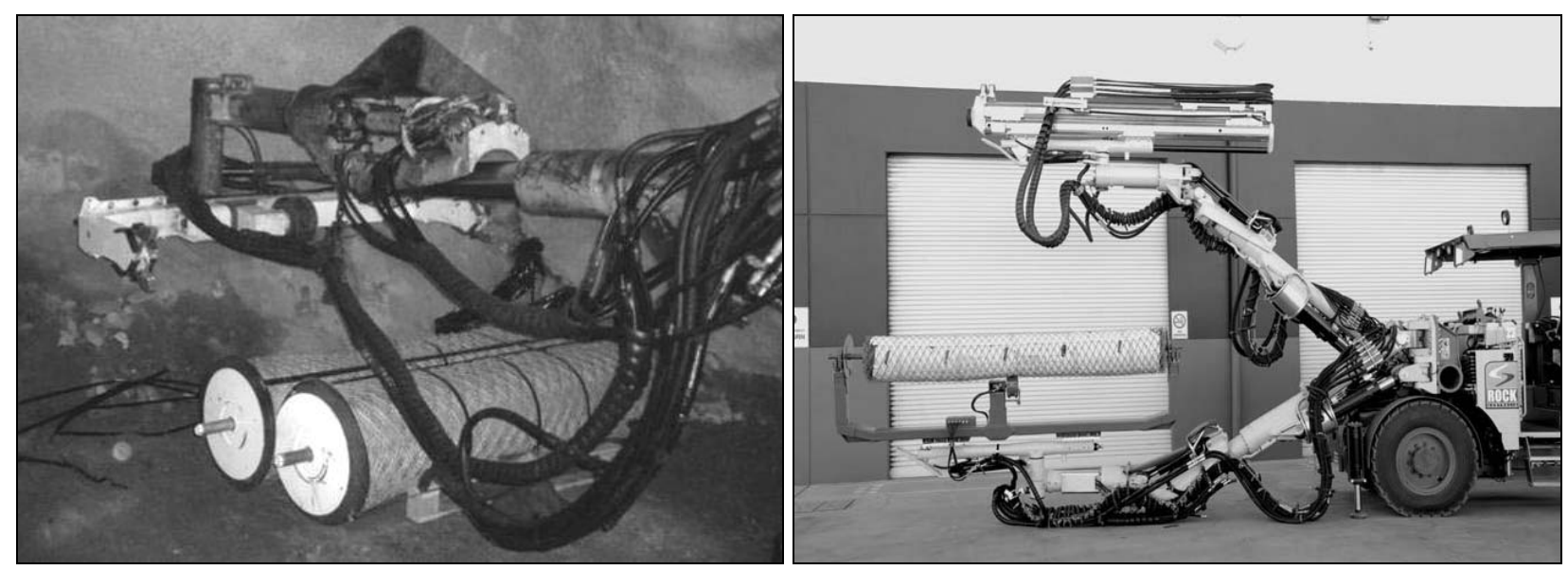

Figure 11 ROCK MESHA mounted on a jumbo boom picks up the roll of mesh automatically (left) and a $3.5 \mathrm{~m}$ wide handler mounted on a twin boom jumbo (right)

The handler is manipulated from the cabin of the drill to pick up a roll of TECCO or DELTAX mesh, minimising physical manual handling. The mesh can then be positioned on the walls and backs for bolting, using the drilling component of the opposite boom.

The system reduces manual handling and personnel exposure during the installation process, reduces support cycle times, enables the mesh to follow the rock surface contours more closely - reducing unravelling/ bagging of material in voids. No personnel are exposed to unsupported ground, due to the ability of the jumbo to pick-up the mesh roll cassette with the manipulator arm. 


\subsection{In situ installation trial in Switzerland}

In order to test and commission the mesh handler, in situ trials were carried out in Australia and Switzerland. The $3.5 \mathrm{~m}$ width mesh handler was fitted on an Atlas Copco Rocket Boomer which is owned and operated by the test facility in Switzerland. The drilling jumbo has three arms, two for drilling and the middle one with a basket. The feed was removed from one of the booms and replaced by the mesh handler. The existing drilling hydraulic circuit was used to control the functions of the mesh handler (Figure 12).

The intention of this trial was to find out in more detail about the installation underground for different mesh types with the width of $3.50 \mathrm{~m}$. The mesh products used were the TECCO G80/4, TECCO G65/3 and DELTAX G80/2, all of which could be installed perfect.

The spike plate worked well and was always moved into the right orientation during installation. From the trial it was found that the plate was too small for the G80 meshes, therefore we enlarged the spike plate for future applications.
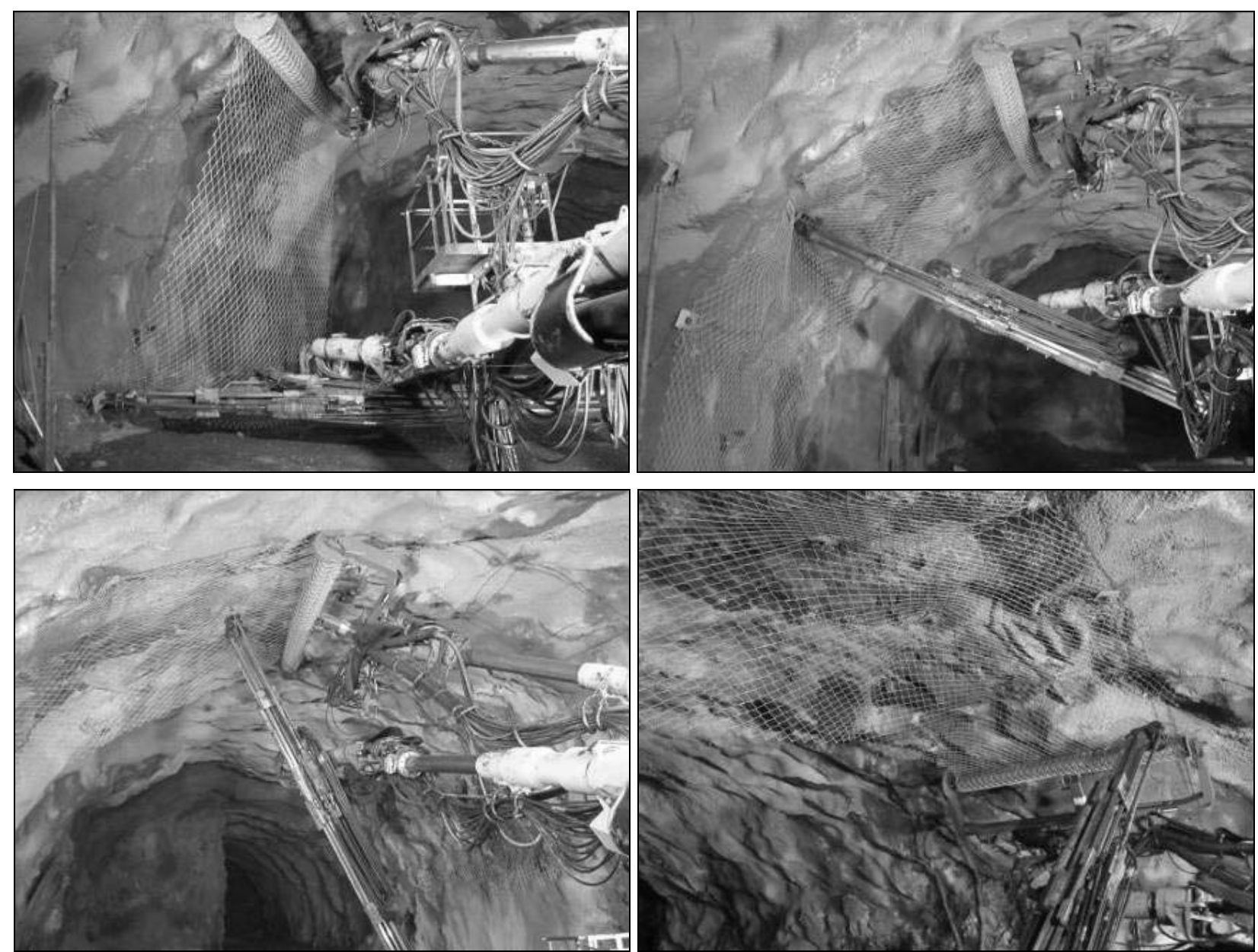

Figure 12 Installation sequence of the TECCO or DELTAX mesh with a twin-boom jumbo in Switzerland

There were concerns that the mesh would 'balloon' away from the wall and allow scats and larger rocks to accumulate in these bubbles. This was not the case, once the mesh had been anchored to the walls and backs, it was noted that the mesh had followed the contours of the rock closely and pulled tightly into the wall giving a smooth and even texture. 

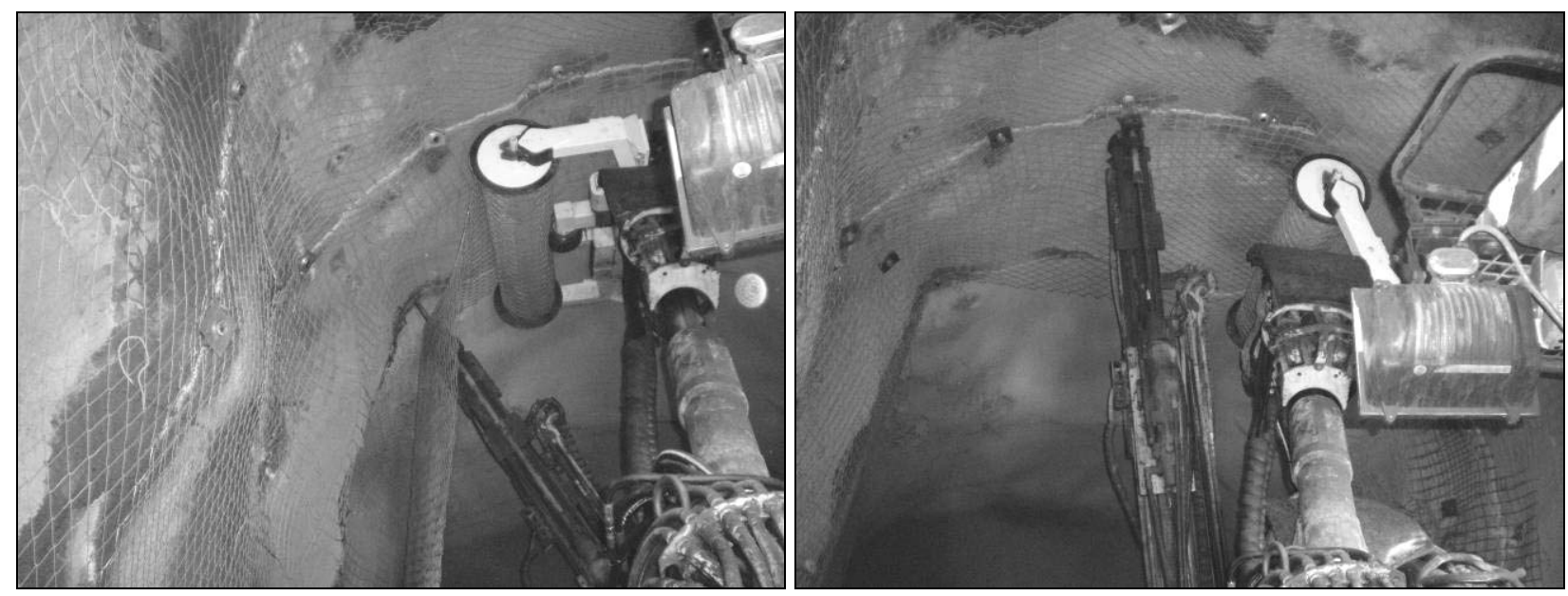

Figure 13 Installation with the MESHA in an underground mine in Western Australia

All the installation trials showed that it was possible to install the high-tensile chain-link mesh in $40 \%$ to $50 \%$ less time than standard weld mesh sheets, even though the operators were doing it for the first time. With an optimisation of the installation process, it will be possible to have an even more rapid meshing cycle without compromising the safety of the operation.

\section{Conclusions}

After successfully testing the high-tensile chain-link mesh under both static and dynamic conditions, it was shown that this kind of mesh is suitable for ground support in potential rockburst areas and also in highdeformation ground conditions. In contrast to shotcrete or fibrecrete, the rock remains visible for inspection by geotechnical personnel. For rockburst conditions, suitable bolts and plates have to be chosen to combine with the high-tensile mesh. The system can be dimensioned with the calibrated numerical model. With the use of the ROCK MESHA, this new type of mesh can be installed easily and more quickly than welded sheets of mesh.

With mechanised application, the high-tensile chain-link mesh reduces application time and allows for optimising the work cycles. Due to the high strength of the mesh, bolt spacings could also be increased. High-tensile mesh with a smaller diameter could be used as reinforcement of shotcrete. It can be concluded that both the high-tensile chain-link mesh and its fully mechanised installation can significantly increase the safety of mining personnel, the quality of the installed ground support and the speed of mining development.

\section{References}

Morton, E., Thompson, A., Villaescusa, E. and Roth, A. (2007) Testing and analysis of steel wire mesh for mining applications of rock surface support, ISRM Symposium, Lisbon, Portugal.

Player, J., Villaescusa, E. and Thompson, A. (2004) Dynamic testing of rock reinforcement using the momentum transfer concept, Ground Support Symposium, Perth, Australia, pp. 327-339.

Player, J., Morton, E., Thompson, A. and Villaescusa, E. (2008) Static and dynamic testing of steel wire mesh for mining applications of rock surface support, in Proceedings Sixth International Symposium on Ground Support in Mining and Civil Engineering Construction, Cape Town, South Africa, pp. 693-706.

Roth, A., Windsor, C., Coxon, J. and de Vries, R. (2004) Performance assessment of high-tensile steel wire mesh for ground support under seismic conditions, Ground Support Symposium, Perth, Australia, pp. 589-594.

Thompson, A., Player, J. and Villaescusa, E. (2004) Simulation and analysis of dynamically loaded reinforcement systems, Ground Support Symposium, Perth, Australia, pp. 341-355.

Torres, J.A. (2002) TECCO mesh, evaluation TECCO G80, technical report, University of Cantabria, Spain, pp. 1-27.

Villaescusa, E. (2009) Dynamic testing of ground support elements, M349A Quarterly Progress Reports March 2009, Western Australian School of Mines, Kalgoorlie, Australia.

Volkwein, A., Anderheggen, E. and Grassl, H. (2002) Numerical simulation of highly flexible rockfall protection systems, 5th World Congress on Computational Mechanics, Vienna, Austria, pp. 224-230.

Volkwein, A. (2004) Numerical simulation of flexible rockfall protection systems, dissertation ETH, Zurich, Switzerland. 